\title{
Reactivity and effectiveness of traditional and novel ligands for multi-micronutrient fertilization in a calcareous soil
}

\author{
Sandra López-Rayo, Paloma Nadal and Juan J. Lucena* \\ Department of Agricultural and Food Chemistry, Faculty of Science, Autonomous University of Madrid, Madrid, Spain
}

\section{OPEN ACCESS}

Edited by:

Raul Antonio Sperotto, Centro Universitário UNIVATES, Brazil

Reviewed by: Roberto Pinton,

University of Udine, Italy

Jose M. Garcia-Mina, University of Navarra, Spain

*Correspondence:

Juan J. Lucena,

Department of Agricultural and Food

Chemistry, Faculty of Science (Módulo 10), Autonomous University

of Madrid, Avenida Francisco Tomás y

Valiente, 7, Madrid 28049, Spain

juanjose.lucena@uam.es

Specialty section:

This article was submitted to

Plant Nutrition,

a section of the journal

Frontiers in Plant Science

Received: 17 July 2015 Accepted: 03 September 2015 Published: 23 September 2015

Citation:

López-Rayo S, Nadal P and Lucena JJ (2015) Reactivity and effectiveness of traditional and novel ligands

for multi-micronutrient fertilization in a calcareous soil.

Front. Plant Sci. 6:752. doi: $10.3389 /$ fpls.2015.00752
This study compares the effectiveness of multi-micronutrient formulations containing iron (Fe), manganese $(\mathrm{Mn})$, and zinc $(\mathrm{Zn})$ with traditional (EDTA, DTPA, HEEDTA, and $\mathrm{EDDHA}_{\mathrm{m}}$ ) or novel chelates (o,p-EDDHA, S,S-EDDS, and IDHA) and natural complexing agents (gluconate and lignosulfonate). The stability and reactivity of the formulations were studied on batch experiments with calcareous soil and by speciation modeling. Formulations containing traditional ligands maintained higher Mn but lower Zn concentration in soil solution than the novel ligands. The gluconate and lignosulfonate maintained low concentrations of both $\mathrm{Mn}$ and $\mathrm{Zn}$ in soil solution. Selected formulations were applied into calcareous soil and their efficacy was evaluated in a pot experiment with soybean. The formulation containing DTPA led to the highest Zn concentration in plants, as well as the formulation containing S,S-EDDS in the short-term, which correlated with its biodegradability. The application of traditional or novel ligands in formulations did not result in sufficient plant Mn concentrations, which was related to the low Mn stability observed for all formulations under moderate oxidation conditions. The results highlight the need to consider the effect of metals and ligands interactions in multi-nutrient fertilization and the potential of S,S-EDDS to be used for Zn fertilization. Furthermore, it is necessary to explore new sources of $\mathrm{Mn}$ fertilization for calcareous soils that have greater stability and efficiency, or instead to use foliar fertilization.

Keywords: o,p-EDDHA, S,S-EDDS, IDHA, micronutrient chelates, fertilizers

\section{Introduction}

Micronutrients contribute greatly to plant health, yield and quality, which are the primary concerns of the agricultural industry (Lindenmayer, 2007). Fertilization with iron (Fe), manganese (Mn), and zinc $(\mathrm{Zn})$ is common in calcareous soils with high $\mathrm{pH}$ as these micronutrients are not available for plants. Other factors such as low soil organic matter, high clay content, and waterlogged soils

Abbreviations: AAS, atomic absorption spectroscopy; CND, compositional nutrition diagnosis; DTPA, diethylene diamine pentacetic acid; $\mathrm{EDDHA}_{m}$, mixture of EDDHA isomers and polycondensate products from industrial synthesis; EDTA, ethylene diamine tetraacetic acid; Gl, gluconic acid; HEEDTA, hydroxyethyl ethylene diamine triacetic acid; HPLC, high performance liquid chromatography; IDHA, $N$-(1,2-dicarboxyethyl)-D,L-aspartic acid; LS, lignosulfonic acid; $o, o$-EDDHA, ethylene diamine- $N, N^{\prime}$-bis(2-hydroxy phenyl) acetic acid; $o, p$-EDDHA, ethylene diamine $N$-(2-hydroxy phenyl acetic acid)$N^{\prime}$-(4-hydroxy phenyl acetic acid); p,p-EDDHA, ethylene diamine $N, N^{\prime}$-bis(4-hydroxy phenyl acetic) acid; S,S-EDDS, ethylene diamine disuccinic acid. 
contribute to the low availability of $\mathrm{Fe}, \mathrm{Mn}$, and $\mathrm{Zn}$ to plants (Aye, 2011). Micronutrient fertilizers are applied directly to soils, in nutrient solutions through fertigation systems or as foliar sprays. However, the interactions between soil and fertilizer may reduce element availability following soil applications of fertilizer. Micronutrient fertilization is traditionally done using inorganic compounds or recalcitrant chelates such as EDTA, DTPA, or HEEDTA (Laurie et al., 1991). The most effective chelating agents that provide Fe to neutral and alkaline soils are diamino-diphenolic-dicarboxylic acids, mainly o, $o$-EDDHA and analogous (Norvell, 1991; Lucena, 2006; Nadal et al., 2012). However, the industrial synthesis of commercial EDDHA yields a mixture of isomers, $o, o$-EDDHA, $o, p$-EDDHA, and $p, p$-EDDHA as well as polycondensate byproducts in variable amounts (Gómez-Gallego et al., 2002; Hernández-Apaolaza et al., 2006; this ligand mixture is named $\mathrm{EDDHA}_{m}$ in this paper to better discern it from the other materials). The $o, o$-EDDHA and analogous ligands, chelated with Fe present the most suitable properties as Fe fertilizer, due to their low reactivity in calcareous soil and high efficiency in supplying Fe to plants (Rojas et al., 2008; Schenkeveld et al., 2010; Nadal et al., 2012), while the $o, p$ EDDHA has a lower efficacy in calcareous soil mainly due to its high reactivity with soil components (García-Marco et al., 2006).

One potential way to improve micronutrient fertilization is to replace the traditional and recalcitrant chelating agents by novel ligands, especially with those that have less environmental impact. S,S-EDDS (Vandevivere et al., 2001), IDHA (Nawrocki et al., 2009), or gluconate are interesting due to their high biodegradability. The use of byproducts is another alternative, such as the lignosulfonates coming from the food and paper industry (Gangloff et al., 2006; Akay and Kaya, 2007) or the ligand $o, p$-EDDHA from the industrial synthesis of EDDHA $m$.

Recent works have evaluated the effectiveness of the application of $\mathrm{Fe}$ or $\mathrm{Zn}$ chelates of IDHA and S,S-EDDS Fe in several plant species, mainly under hydroponic conditions or following foliar applications (González et al., 2007; Villén et al., 2007a; Lucena et al., 2008; Rodríguez-Lucena et al., 2010a,b; López-Rayo et al., 2013). Iron and $\mathrm{Zn}$ lignosulfonates have also shown promising results for plant nutrition (Álvarez and Rico, 2003; Martín-Ortiz et al., 2009; Rodríguez-Lucena et al., 2010a; Benedicto et al., 2011).

In a previous study, the mentioned synthetic chelating agents and natural complexes described here were evaluated as sources for $\mathrm{Mn}$ and $\mathrm{Zn}$ nutrition in mixed formulations with $o, o-\mathrm{EDDHA} / \mathrm{Fe}^{3+}$ or $\mathrm{EDDHA}_{m}-\mathrm{Fe}$ in a high $\mathrm{pH}$, soil-free environment using both models and experimental assays (LópezRayo et al., 2012, 2015). In these conditions, the $o, p$-EDDHA Mn and $\mathrm{Zn}$ chelates, and S,S-EDDS Zn chelates were more effective in providing $\mathrm{Mn}$ and/or $\mathrm{Zn}$ to soybean stressed plants, when applied along with $o, o$-EDDHA/ $\mathrm{Fe}^{3+}$, than traditional sources such as EDTA or sulfates. Mixing different metal-chelates in the fertilizer formulation contribute to modify the $\mathrm{Zn}$ and $\mathrm{Mn}$ availability to plants.

Despite the promising results found for hydroponicgrowing conditions by López-Rayo et al. (2015), the results obtained by mixing chelates with different chelating agents cannot be extended to soil conditions. The interactions between soil and fertilizer may reduce element availability. The reactivity and sorption processes within the soil components, the buffering capacity of the bicarbonate in soil and the high $\mathrm{pH}$ are the main factors controlling the effectiveness of micronutrient fertilizers in the soil environment.

Therefore, the stability of a metal chelate in soil solution depends on its formation and the equilibrium constant, which is dependent on the ligand type, $\mathrm{pH}$, and salt concentrations (Lucena, 2006), but also to other external factors such as time and soil texture (Norvell, 1991). The update of the thermodynamic database of model programs such as the VMINTEQ with the recently described stability constants S,S-EDDS, IDHA, and $o, p$ EDDHA with Mn and Zn (Yunta et al., 2012) allows for the prediction of the stability of metal chelates in soil conditions. However, kinetic aspects are not considered in the models, and additional batch experiments are frequently necessary for a complete characterization.

In this work we considered the efficacy of multi-micronutrient formulations containing $\mathrm{Fe}, \mathrm{Mn}$, and $\mathrm{Zn}$ combined with chelate or in complexed forms: we analyzed their stability and reactivity in soil and their efficacy to provide these micronutrients to soybean plants grown on calcareous soil. The objective was to compare novel sources for $\mathrm{Mn}$ and $\mathrm{Zn}$ by the ligands $o, p$ EDDHA, S,S-EDDS, IDHA, lignosulfonate, and gluconate with common chelating agents (EDTA, DTPA, and HEEDTA) used in fertilization. This work is an extension of two previous studies in which the stability and the efficacy of similar mixed formulations were evaluated in hydroponic systems (López-Rayo et al., 2012, 2015).

\section{Materials and Methods}

\section{Batch Incubation Experiment and Modeling}

Several combinations of formulations containing $\mathrm{Fe}, \mathrm{Mn}$, and $\mathrm{Zn}$ were evaluated. Six chelating agents (o,p-EDDHA, EDTA, HEEDTA, DTPA, IDHA, and S,S-EDDS) and two natural complexing agents (lignosulfonate and gluconate) chelated/complexed by $\mathrm{Mn}$ and $\mathrm{Zn}$ were combined with $\mathrm{Fe}$ as $o, o-\mathrm{EDDHA} / \mathrm{Fe}^{3+}$ or as commercial $\mathrm{EDDHA}_{m}-\mathrm{Fe}$ (3.14 and $1.72 \%$ of $\mathrm{Fe}$ chelated by $o, o$-EDDHA and $o, p$-EDDHA, respectively, and $2 \%$ of additional $\mathrm{Fe}$ was stabilized by other compounds, determined by the HPLC method; Comité Européen de Normalisation [CEN], 2008, 15452/2008). A combination without Fe was also studied for comparison. All formulations were prepared according to López-Rayo et al. (2015) using standard reagents $\left[\mathrm{H}_{4} o, o\right.$-EDDHA (Promochem, 93.9\%), $\mathrm{H}_{4} o, p-$ EDDHA (Syngenta Agro, 93.1\%), $\mathrm{Na}_{2}$ EDTA (Tritriplex III, Merck, 99\%), $\mathrm{H}_{5}$ DTPA (Tritriplex V, Merck, 99\%), $\mathrm{Na}_{3}$ HEEDTA (Sigma, 98\%), $\mathrm{Na}_{4} \mathrm{IDHA}$ (Adob PPC, 78.1\%), $\mathrm{Na}_{3} \mathrm{~S}, \mathrm{~S}-\mathrm{EDDS}$ (Fluka, solution at 35\%), and sodium gluconate (PRS, Panreac, 98\%)]. Manganese and Zn lignosulfonates were prepared based on the complexing capacity of the LS (Borresperse 350, Lignotech Ibérica S.A.) with $\mathrm{Mn}$ and $\mathrm{Zn}$ by the method described by Villén et al. (2007b).

Soil incubations were performed according to the method described by Álvarez-Fernández et al. (2002). Twenty five 
milliliters of formulation solutions containing $4.48 \times 10^{-4} \mathrm{M}$ Fe, $1.71 \times 10^{-4} \mathrm{M} \mathrm{Mn}, 9.56 \times 10^{-5} \mathrm{M} \mathrm{Zn}, 0.01 \mathrm{M} \mathrm{CaCl}_{2}$, and $0.01 \mathrm{M}$ HEPES buffer ( $\mathrm{pH} 7.5$ ) were added to $5.0 \mathrm{~g}$ of calcareous soil from Picassent (Valencia, Spain, characteristics described in Table 1). Prior to this, the soil was sterilized by autoclaving for $1 \mathrm{~h}$ at $121^{\circ} \mathrm{C}$ to avoid the effect of rewetting dry soils on the microbial activity, which could affect to the solubility of $\mathrm{Mn}$ and other elements. A molar Fe:Mn:Zn ratio of 4:1.5:1 was chosen, based on the ratio typically used in commercial multi-micronutrient fertilizers (Liñán, 2014). After $1 \mathrm{~h}$ of agitation at $56 \mathrm{rpm}$, samples were allowed to stand for 3 and 7 days at $25^{\circ} \mathrm{C}$. Then, solutions were filtered, and $\mathrm{pH}$ and $\mathrm{Fe}, \mathrm{Mn}, \mathrm{Zn}$, and $\mathrm{Cu}$ in solution were analyzed by AAS (Perkin-Elmer AAnalyst ${ }^{\mathrm{TM}} 800$ ).

The stability of the formulations containing chelates with known stability constants ( $o, o$-EDDHA, $o, p$-EDDHA, IDHA, S,SEDDS, EDTA, DTPA, and HEEDTA; López-Rayo et al., 2012; Yunta et al., 2012) in calcareous soil was analyzed by the modeling software VMINTEQ 3.0. An additional combination with $\mathrm{MnSO}_{4}$ and $\mathrm{ZnSO}_{4}$ was also included. A wide range of soil conditions were considered, which can be found in typical well aerated soils: $\mathrm{pH}$ range (5-9.5), and slightly reducing redox potential ( $\mathrm{pe}+\mathrm{pH} 15)$, or oxidizing conditions ( $\mathrm{pe}+\mathrm{pH} 18)$. Further explanation of the calcareous soil model is shown in the Supplementary Material.

\section{Biological Experiment}

Soybean (Glycine max L. cv Klaxon) seeds were germinated in hydroponics as described in López-Rayo et al. (2015), first in a diluted completed nutrient solution for 7 days and then, in a full-strength nutrient solution without $\mathrm{Mn}, \mathrm{Zn}$, and $\mathrm{Cu}$, and with a low Fe concentration (10.0 $\mu \mathrm{M}$ FeEDTA) to maintain a low Fe level for 4 days (see Supplementary Material for further information).

Then, three seedlings per pot were transplanted to $1 \mathrm{~L}$ pots filled with $1 \mathrm{~kg}$ soil-sand ( $0.7 \mathrm{~kg}$ soil and $0.3 \mathrm{~kg}$ sand) mixture (sand: $975 \mathrm{~g} \mathrm{~kg}^{-1} \mathrm{CaCO}_{3}, 1-3 \mathrm{~mm}$ size; see soil characteristics in Table 1). This soil has been previously shown to produce multi-micronutrient deficiencies in soybean (Nadal et al., 2012). The pots were placed in a Dycometal-type CCK growth chamber provided with fluorescent and sodium vapor lamps with a $16 \mathrm{~h}$, $30^{\circ} \mathrm{C}$ and $50 \%$ humidity day, and an $8 \mathrm{~h}, 25^{\circ} \mathrm{C}$ and $70 \%$ humidity night regime. Pots were daily irrigated up to $80 \%$ saturation with full-strength macronutrient solution buffered at $\mathrm{pH} 8.2$ with $0.1 \mathrm{~g} \mathrm{~L}^{-1}$ of lime and $0.1 \mathrm{~g} \mathrm{~L}^{-1}$ of sodium bicarbonate to simulate bicarbonate irrigation water as that commonly available in calcareous soil areas. Treatments were applied on the top of the soil surface along with the irrigation solution 7 days after transplanting when plants showed deficiency symptoms. Five multi-nutrient treatments with four replicate pots were compared following the application of $\mathrm{Fe}, \mathrm{Mn}$, and $\mathrm{Zn}$ chelates and one control without $\mathrm{Mn}$ and $\mathrm{Zn}$.

In three of the treatments, $o, o-\mathrm{EDDHA} / \mathrm{Fe}^{3+}$ was combined with $\mathrm{Mn}$ and $\mathrm{Zn}$ as EDTA (T-1), DTPA (T-2), or S,S-EDDS (T-3) chelates. Since the single ligand $o, p$-EDDHA is not commercially available, the ligand mixture $\mathrm{EDDHA}_{m}$ was used to complex $\mathrm{Fe}$, $\mathrm{Mn}$, and $\mathrm{Zn}$, in T-4 to assay the $o, p$-EDDHA. Similar to T-4, T5 combined $\mathrm{EDDHA}_{m}$ complexed with both Fe and $\mathrm{Zn}$, but $\mathrm{Mn}$ was chelated by EDTA. The doses applied were $\left(\mu \mathrm{mol} \mathrm{kg}{ }^{-1}\right): 17.9$ $\mathrm{Fe}, 6.83 \mathrm{Mn}$, and 3.82 $\mathrm{Zn}$. Each chelate solution was prepared individually and mixed just before their application into the pot. To avoid $\mathrm{Cu}$ deficiencies (that may alter the plant response to the treatments), $\mathrm{Cu}$ was also added $\left(2.36 \mu \mathrm{mol} \mathrm{kg}{ }^{-1}\right)$ in the same chelate form as those used for $\mathrm{Mn}$ and $\mathrm{Zn}$. The ligand EDDHA $_{m}$ used in T-4 and T-5 was a liquid solution containing $9.2 \% o, o$-EDDHA, and 5.1\% $o, p$-EDDHA (w/w), which was determined by the method EN 15452:2008 (Comité Européen de Normalisation [CEN], 2008). The total complexing capacity determined as titrimetric purity (Yunta et al., 2003) was 21\% $(\mathrm{w} / \mathrm{w})$, therefore, $4.6 \%(\mathrm{w} / \mathrm{w})$ corresponds with other complexing agents such as polycondensation products. Taking into account this distribution and the ligand stability constants (López-Rayo et al., 2012), the composition of treatment T-4 should be $\mathrm{Fe}$ chelated by $o, o$-EDDHA (86.0\%) and $o, p$-EDDHA (14.0\%) and $\mathrm{Mn}, \mathrm{Zn}$, and $\mathrm{Cu}$ complexed by $o, p$-EDDHA (19.5\%) and other complexing agents (80.5\%). Similarly, in T-5, this composition would be Fe chelated by $o, o$-EDDHA (67.2\%) and $o, p$-EDDHA $(32.8 \%)$ and $\mathrm{Zn}$ and $\mathrm{Cu}$ complexed by $o, p$-EDDHA $(3.3 \%)$ and other complexing agents (96.7\%). The control without $\mathrm{Mn}$ and $\mathrm{Zn}$ only contained $o, o$-EDDHA/Fe ${ }^{3+}$. Since the main objective of the paper was to compare the application of mixed formulations, a negative control (without any chelate) was not used.

\section{Plant and Soil Analysis}

The SPAD Index (Minolta SPAD-502) was used as an indicator of the relative chlorophyll content after the treatment application every 3-4 days throughout the experiment. Plant material was sampled 7 and 20 days after the application of the treatments (DAT). In the first sampling time, two complete plant tops per pot were sampled and only one in the second sampling time. Shoot length (SL) and internode distance (ID) was measured. Leaves and stems were separated and washed as in Álvarez-Fernández et al. (2001), then dried and weighed. Total Fe, Mn, $\mathrm{Zn}$, and $\mathrm{Cu}$ were determined in leaves after dry mineralization by AAS.

On completion of the experiments, the soluble and available $\mathrm{Fe}, \mathrm{Mn}, \mathrm{Zn}$, and $\mathrm{Cu}$ fractions were determined in the soils following the extraction method described by Nadal et al. (2012)

TABLE 1 | Selected chemical characteristics of the agricultural soil used.

\begin{tabular}{|c|c|c|c|c|c|c|c|c|c|c|c|}
\hline \multirow[b]{2}{*}{ Texture } & \multicolumn{2}{|c|}{$\mathrm{pH}$} & \multirow{2}{*}{$\begin{array}{l}\mathrm{EC} \\
\mathrm{dS} \mathrm{m}^{-1}\end{array}$} & \multirow{2}{*}{$\begin{array}{l}\text { OM } \\
\mathbf{g ~ k g}^{-1}\end{array}$} & \multirow{2}{*}{$\frac{\mathrm{N}_{k j}}{\mathrm{~g} \mathrm{~kg}^{-1}}$} & \multicolumn{2}{|c|}{$\mathrm{CaCO}_{3}, \mathrm{~g} \mathrm{~kg}^{-1}$} & $\mathrm{Fe}^{a}$ & Mn & $\mathrm{Cu}$ & Zn \\
\hline & $\mathrm{H}_{2} \mathrm{O}$ & $\mathrm{KCl}$ & & & & Total & Active & \multicolumn{4}{|c|}{$\mathbf{m g ~ k g} \mathbf{~}^{-1}$} \\
\hline Sandy loam & 7.70 & 7.10 & 0.270 & 9.2 & 0.30 & 380 & 89 & 2.3 & 1.9 & 0.7 & 2.5 \\
\hline
\end{tabular}

aMicronutrients determined as in Soltanpour and Schwab (1977). 
with water and DTPA solutions (Soltanpour and Schwab, 1977). Extracts were acidified to $1 \%$ with $\mathrm{HNO}_{3}(65 \%$, Merck) and analyzed by AAS.

\section{Data Analysis}

Data were submitted to analysis of variance (ANOVA) using SPSS statistical software (version 19.0; SPSS Inc., Chicago, IL, USA). Means of the parameters studied were compared using Duncan post hoc test to evaluate significantly different treatments.

A foliar diagnosis was additionally performed by the CND method, which takes all possible nutrient interactions into account, including non-analyzed nutrients. The indices obtained indicate nutrient insufficiency (negative indices) or nutrient efficiency (positive indices) in comparison with a reference treatment (norm). In this experiment, treatment with $\mathrm{Mn}$ and $\mathrm{Zn}$ as EDTA (T-1) was used as the norm, since this is the combination most commonly applied in field; hence, positive or negative CND indices indicate a more or less equilibrated nutrition compared to using EDTA on a particular element.

\section{Results}

\section{Stability and Reactivity of Multi-Micronutrient Formulations with Soil: Batch Experiment and Prediction Model}

The solution $\mathrm{pH}$ after the batch experiment with calcareous soil was in the range of 7.3-7.8. The percentages of $\mathrm{Fe}, \mathrm{Mn}$, and $\mathrm{Zn}$ remaining in solution of the evaluated formulations are presented in Figure 1.

The use of the novel ligands $o, p$-EDDHA, IDHA, and S,SEDDS did not reach the high Mn levels observed for the traditional ligands EDTA, HEEDTA, or DTPA (Figure 1). To a lesser extent, $\mathrm{Zn}$ in solution was lower for combinations with $o, p$-EDDHA and IDHA than for the traditional combinations. However, S,S-EDDS maintained the highest $\mathrm{Zn}$ concentrations in solution and had the greatest recovery of $\mathrm{Fe}$ from soil when Fe was not applied. Furthermore, the $\mathrm{Cu}$ recovered in solution (and expressed as Fe displacement by $\mathrm{Cu}$ ) increased considerably when S,S-EDDS was used irrespectively of the Fe source used. Low $\mathrm{Mn}$ and $\mathrm{Zn}$ concentrations in solutions were maintained by the natural complexes LS and Gl. The amount of Fe recovered in the formulations with $o, o-\mathrm{EDDHA} / \mathrm{Fe}^{3+}$ were around $10 \%$ higher than those with $\mathrm{EDDHA}_{m}-\mathrm{Fe}$, and similar after 3 or 7 days of interaction. Formulations without Fe dissolved more Fe from the soil after 7 days than after 3 days. Similar Mn concentrations in solution after 3 and 7 days were obtained when $\mathrm{Fe}$ was applied as $o, o-\mathrm{EDDHA} / \mathrm{Fe}^{3+}$. When $\mathrm{EDDHA}_{m}$-Fe was used, the Mn concentration in solution was slightly reduced after 7 days when applied as HEEDTA, DTPA, IDHA, or S,S-EDDS chelates. In general, $\mathrm{Zn}$ concentrations in solution after 7 days were lower than after 3 days with both $\mathrm{Fe}$ sources. Dissolved $\mathrm{Cu}$ was also similar at both times and with all combinations, between 0 and $3.5 \%$ in all cases.

In Figure 2, the distribution of the ligand (expressed as molar percentage) in the theoretical model, initially included as $\mathrm{Mn}$ (initial value 64\%) and $\mathrm{Zn}$ chelates (initial value $36 \%$ ) is presented for each formulation. In most of the formulations, both chelated $\mathrm{Zn}$ and $\mathrm{Mn}$ were partially or totally displaced in soil conditions. In the acid-neutral soils, this was mainly due to the formation of the Fe chelates, which decreased in the oxidized soil. A complete $\mathrm{Mn}$ and $\mathrm{Zn}$ displacement by $\mathrm{Fe}$ took place in the formulations that were applied as $o, o$-EDDHA and $o, p$-EDDHA. In agreement with this, the formulations that were applied as sulfates did not produce any chelated Mn or Zn.

The ability of the chelating agents to keep the Mn chelated at slightly reducing $(\mathrm{pe}+\mathrm{pH}=15)$ and neutral to calcareous soil conditions were: DTPA $>$ EDTA $>$ HEEDTA $>$ S,S-EDDS $\sim$ IDHA (IDHA $>$ S,S-EDDS in neutral soil, and S,S-EDDS $>$ IDHA in calcareous soil). The EDTA and HEEDTA kept the total initial quantity of Mn introduced as chelate while DTPA was able to chelate more $\mathrm{Mn}$ from soil (indicated by values higher than $64 \%$ ). When oxidizing conditions were considered ( $\mathrm{pe}+\mathrm{pH}=18$ ) none of the chelating agents were able to keep Mn chelated at all $\mathrm{pH}$ levels. The behavior of $\mathrm{Zn}$ was different, resulting in a higher amount of $\mathrm{Zn}$ chelated at oxidizing conditions. The relative ability of the chelating agents to keep the $\mathrm{Zn}$ chelated in this case within the $\mathrm{pH}$ range of calcareous soil was S,S-EDDS $\sim$ DTPA $>$ HEEDTA $>$ EDTA $>$ IDHA. The maximum at $56 \%$ corresponds to the maximum solubility of $\mathrm{Zn}$ in a soil (Lindsay and Schwab, 1982). At slightly reducing conditions, only S,S-EDDS maintained this maximum amount of $\mathrm{Zn}$ chelated.

In all the conditions studied, the combinations containing sulfate, $o, p$-EDDHA or $o, o$-EDDHA kept none chelated Mn or $\mathrm{Zn}$, which was associated with the formation of Fe chelates in the case of EDDHA isomers. The percentage obtained for $\mathrm{Cu}$ was similar in all formulations and conditions and did not reach values higher than $3.5 \%$ in any case.

\section{Efficacy of Formulations to Supply Micronutrients to Soybean under a Calcareous Soil}

SPAD readings were taken for all leaf stages during the experiment, but only SPAD values measured for the youngest, fully expanded leaf (third leaf stage), expressed as SPAD increments (with respect to the application day, SPAD index ${ }_{0 D A T}=10.6 \pm 1.3$, mean \pm SE), are shown in Table 2 . The formulation with MnZn-EDTA (T-1) had the lowest values at 7 DAT and no differences were observed among the other treatments or for the control. After 20 days, the treatment with MnZn-S,S-EDDS (T-3) showed the greatest SPAD increase.

At 7 DAT, the formulation with MnZn-EDTA produced the highest stem DW and MnZn-S,S-EDDS the lowest. A similar tendency was observed for the SL (Table 2). At 20 DAT, MnZnEDTA also produced the highest leaf DW and MnZn-EDDHA ${ }_{m}$ the lowest. Other treatments were not significantly different from each other.

Micronutrient concentrations in leaves (Table 3) were, in general, higher at 7 DAT than at 20 DAT. Only the formulation with MnZn-DTPA maintained a stable Zn concentration between the first and the second sampling time. The formulation containing MnZn-EDTA produced the highest Fe concentration in leaves 7 DAT despite Fe being applied as $o, o-E D D H A / \mathrm{Fe}^{3+}$ in 


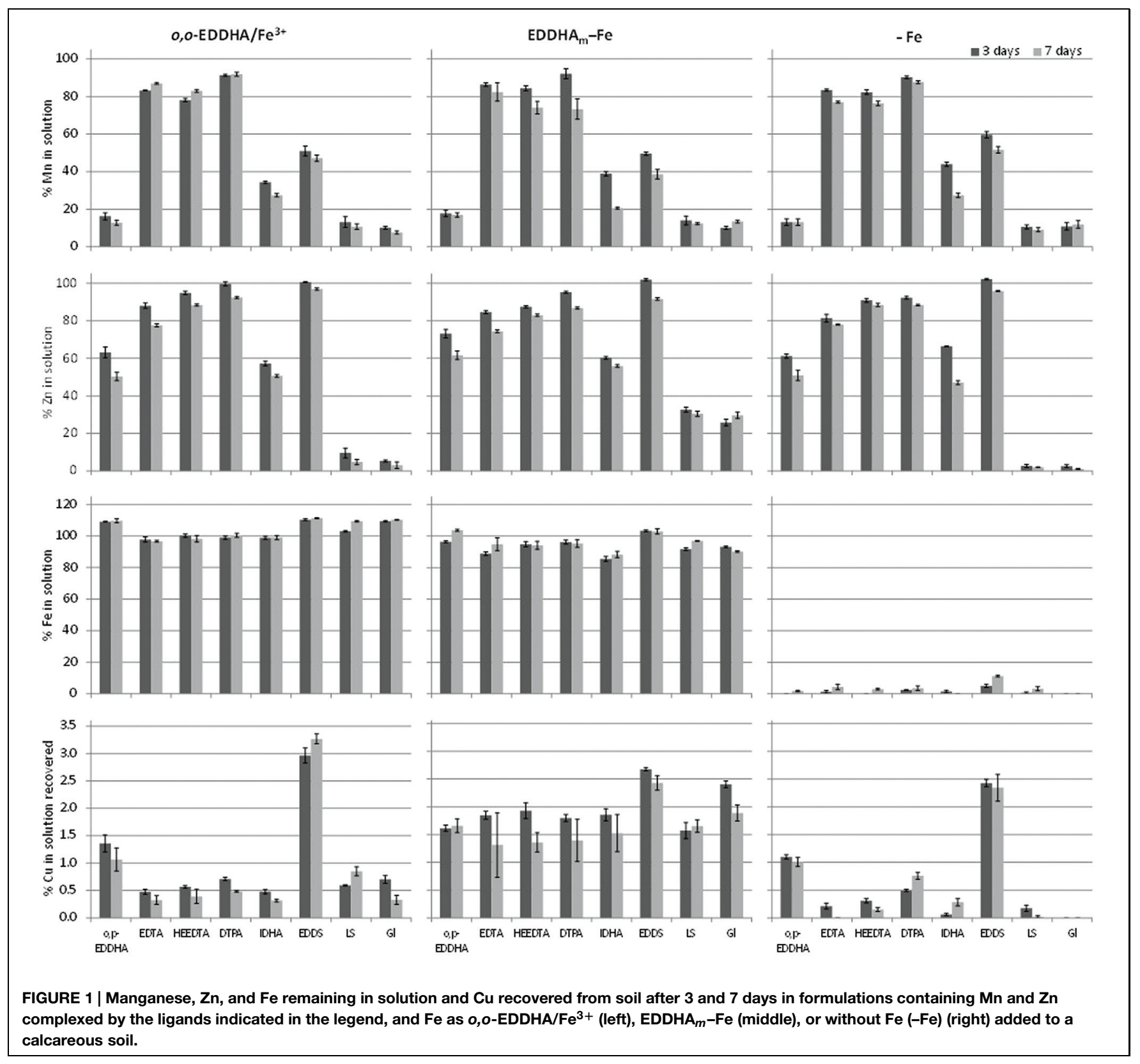

all the treatments. The use of $\mathrm{EDDHA}_{m}$ in the formulations led to a decrease in leaf $\mathrm{Fe}$ concentration as compared to the use of the $o, o$-EDDHA for the later sampling time.

No differences were observed in leaf Mn concentrations at either 7 or 20 DAT. The combination with DTPA resulted in the highest $\mathrm{Zn}$ concentrations at both 7 and 20 DAT. By using S,S-EDDS or EDTA in the formulations, the $\mathrm{Zn}$ concentration increased in a similar way at 7 DAT, but decreased at 20 DAT with the S,S-EDDS treatment. The formulations with $\mathrm{EDDHA}_{m}$ (T-4 and T-5) had lower $\mathrm{Zn}$ concentrations than the other treatments, similar to concentrations in the control in the case of T-4 that reached the lowest values. The Fe/Mn molar ratio indicated quite higher levels in the range of 1.9-4.7, with slight differences between formulations.
Pearson's correlation coefficient was additionally analyzed by comparing mean values from all pairs of nutritional status indices at each sampling time. Positive and significant correlations were found at the end of the assay (20 DAT) between SPAD and $\mathrm{Fe}$ concentration in leaf $\left(0.423^{*}\right)$ and between ID and $\mathrm{Mn}$ concentration in leaf $\left(0.561^{* *}\right)$. The results obtained for $\mathrm{Fe}, \mathrm{Mn}, \mathrm{Zn}$ and $\mathrm{Cu} \mathrm{CND}$ indices at 7 and 20 DAT are shown in Figure 3. All treatments had to negative indices for $\mathrm{Fe}$, with the lowest index for formulation containing FeZnEDDHA $_{m}$ and Mn-EDTA (T-5) at both sampling times. When $\mathrm{Fe}$ was added as $o, o$-EDDHA/ $\mathrm{Fe}^{3+}$, the $\mathrm{Fe}$ indices were close to the norm and similar to the control (containing o,oEDDHA/Fe). A positive $\mathrm{Mn}$ index was only observed when $\mathrm{Mn}$ was applied as EDTA in combination with $\mathrm{EDDHA}_{m}$ 


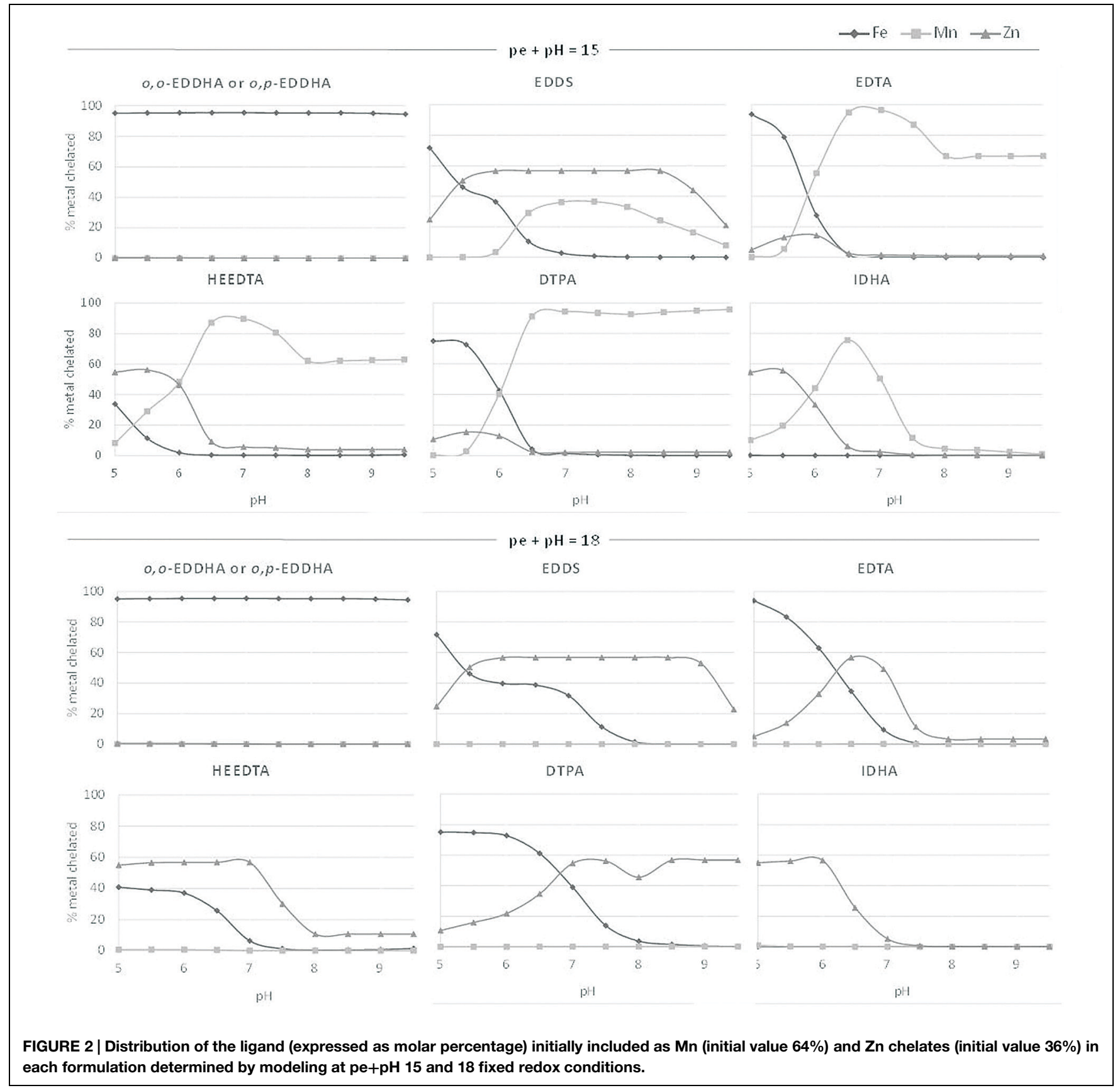

(T-5) at 20 DAT. Large differences were obtained in $\mathrm{Zn}$ indices among the treatments. The formulation with DTPA led to positive values at both sampling times and negative values with all other combinations. The formulation with $\mathrm{EDDHA}_{m}$ (T-4) had a remarkably low $\mathrm{Zn}$ index as compared to other treatments. The range of $\mathrm{Cu}$ indices observed was smaller than those for the other nutrients (Figure 3); for all combinations, indices were positive, and negative for the control.

No differences were found in available $\mathrm{Fe}, \mathrm{Mn}, \mathrm{Zn}$, and $\mathrm{Cu}$ at the end of the experiment (Table 4). The highest micronutrient concentrations in the soluble fraction were found in the formulation with DTPA. The formulation with S,S-EDDS also showed high $\mathrm{Fe}$ and $\mathrm{Mn}$ concentrations in soluble fractions but quite low $\mathrm{Zn}$ concentrations (Table 4).

\section{Discussion}

Both the batch experiment and the modeling showed the same order of stability of the studied chelates in contact with calcareous soil. Also, the experiments showed a competition between $\mathrm{Fe}$, $\mathrm{Mn}$, and $\mathrm{Zn}$ with the ligands which was dependent on two parameters: firstly, the stability of the individual metal chelates 
TABLE 2 | SPAD increment ( $\triangle$ SPAD), Shoot Length (SL), Internodes' Distance (ID) and Dry Weight (DW) of leaf, stem 7 and 20 DAT and roots 20 DAT of soybean plants.

\begin{tabular}{|c|c|c|c|c|c|c|c|c|c|c|c|c|}
\hline & & \multicolumn{5}{|c|}{7 days } & \multicolumn{6}{|c|}{20 days } \\
\hline & & \multirow[b]{2}{*}{$\begin{array}{l}\Delta \text { SPAD } \\
\text { (third } \\
\text { level) }\end{array}$} & \multicolumn{2}{|c|}{ DW (g plant $\left.{ }^{-1}\right)$} & \multirow[b]{2}{*}{$\begin{array}{l}\mathrm{SL} \\
(\mathrm{cm})\end{array}$} & \multirow[b]{2}{*}{$\begin{array}{l}\text { ID } \\
\text { (cm) }\end{array}$} & \multirow[b]{2}{*}{$\begin{array}{l}\Delta \text { SPAD } \\
\text { (third } \\
\text { level) }\end{array}$} & \multicolumn{3}{|c|}{ DW (g plant ${ }^{-1}$ ) } & \multirow[b]{2}{*}{$\begin{array}{l}\text { SL } \\
(\mathrm{cm})\end{array}$} & \multirow[b]{2}{*}{$\begin{array}{l}\text { ID } \\
\text { (cm) }\end{array}$} \\
\hline & & & Leaf & Stem & & & & Leaf & Stem & Root & & \\
\hline $\mathrm{T}-1$ & $\begin{array}{l}\text { o,o-EDDHA/Fe }{ }^{3+} \\
\text { MnZn-EDTA }\end{array}$ & $26.6^{b}$ & $\begin{array}{l}0.517 \\
\mathrm{~ns}\end{array}$ & $0.351^{a}$ & $38.2^{\mathrm{a}}$ & $\begin{array}{l}6.65 \\
\text { ns }\end{array}$ & $30.1^{b}$ & $1.32^{\mathrm{a}}$ & $1.23 \mathrm{~ns}$ & $0.248 \mathrm{~ns}$ & $110 \mathrm{~ns}$ & $\begin{array}{l}13.4 \\
\mathrm{~ns}\end{array}$ \\
\hline $\mathrm{T}-2$ & $\begin{array}{l}\text { o,o-EDDHA/Fe }{ }^{3+} \\
\text { MnZn-DTPA }\end{array}$ & $34.1^{\mathrm{a}}$ & 0.528 & $0.341^{a b}$ & $33.7^{a b}$ & 6.46 & $36.9^{a b}$ & $1.17^{\mathrm{ab}}$ & 1.17 & 0.228 & 108 & 12.7 \\
\hline $\mathrm{T}-3$ & $\begin{array}{l}\text { o,o-EDDHA/Fe }{ }^{3+} \\
\text { MnZn-EDDS }\end{array}$ & $35.0^{\mathrm{a}}$ & 0.432 & $0.268^{b}$ & $28.1^{b}$ & 5.77 & $41.1^{\mathrm{a}}$ & $1.18^{a b}$ & 1.09 & 0.210 & 106 & 12.5 \\
\hline $\mathrm{T}-4$ & FeMnZn-EDDHA $A_{m}$ & $32.7^{a}$ & 0.495 & $0.310^{\mathrm{ab}}$ & $32.9^{a b}$ & 6.16 & $34.0^{b}$ & $1.05^{\mathrm{b}}$ & 1.03 & 0.221 & 108 & 13.6 \\
\hline $\mathrm{T}-5$ & $\begin{array}{l}\text { FeZn-EDDHA } m \\
\text { Mn-EDTA }\end{array}$ & $34.2^{\mathrm{a}}$ & 0.474 & $0.298^{a b}$ & $32.6^{a b}$ & 6.23 & $35.9^{b}$ & $1.33^{a b}$ & 1.30 & 0.230 & 106 & 12.8 \\
\hline Control & $0,0-\mathrm{EDDHA} / \mathrm{Fe}^{3+}$ & $32.9^{a}$ & 0.487 & $0.317^{a b}$ & $33.6^{a b}$ & 6.07 & $34.9^{b}$ & $1.28^{\mathrm{ab}}$ & 1.21 & 0.234 & 98 & 11.5 \\
\hline
\end{tabular}

In each data range, different letters denote significant differences among the treatments according to Duncan's test ( $p<0.05)$. ns, not significant.

TABLE 3 | Fe, Mn, Zn and Cu concentrations ( $m g$ kg ${ }^{1}$ DW) and Fe/Mn molar ratio in leaf (7 and 20 DAT) and root (20 DAT) of soybean plants 7 and 20 DAT.

\begin{tabular}{|c|c|c|c|c|c|c|c|c|c|c|c|}
\hline & & \multicolumn{5}{|c|}{7 days } & \multicolumn{5}{|c|}{20 days } \\
\hline $\mathrm{T}-1$ & o,o-EDDHA/Fe ${ }^{3+}$ MnZn-EDTA & $138^{a}$ & $38.0 \mathrm{~ns}$ & $51.3^{\mathrm{b}}$ & $7.94^{\mathrm{b}}$ & $3.63^{a}$ & $64.6^{\mathrm{ab}}$ & $19.0 \mathrm{~ns}$ & $46.0^{\mathrm{b}}$ & $5.27^{\mathrm{c}}$ & $3.38^{\mathrm{ab}}$ \\
\hline $\mathrm{T}-2$ & o,o-EDDHA/Fe ${ }^{3+}$ MnZn-DTPA & $94.0^{\mathrm{C}}$ & 29.6 & $72.9^{\mathrm{a}}$ & $9.63^{b}$ & $3.22^{\mathrm{a}}$ & $69.8^{\mathrm{a}}$ & 15.1 & $72.9^{\mathrm{a}}$ & $7.29^{a}$ & $4.71^{\mathrm{a}}$ \\
\hline $\mathrm{T}-5$ & FeZn-EDDHA $m$ Mn-EDTA & $101^{c}$ & 35.5 & $34.5^{\mathrm{c}}$ & $10.2^{\mathrm{b}}$ & $2.80^{\mathrm{ab}}$ & $54.6^{\mathrm{b}}$ & 19.8 & $28.1^{c}$ & $5.74^{\mathrm{bc}}$ & $2.75^{\mathrm{b}}$ \\
\hline Control & $0,0-\mathrm{EDDHA} / \mathrm{Fe}^{3+}$ & $121^{\mathrm{b}}$ & 35.8 & $14.0^{\mathrm{d}}$ & $8.12^{\mathrm{b}}$ & $3.36^{\mathrm{a}}$ & $65.5^{\mathrm{ab}}$ & 18.1 & $19.6^{\text {de }}$ & $5.35^{\mathrm{c}}$ & $3.74^{\mathrm{ab}}$ \\
\hline
\end{tabular}

In each data range, different letters denote significant differences among the treatments according to Duncan's test ( $p<0.05)$. ns, not significant.

and, secondly, by the soil properties. This was highlighted when the isomers $o, o$-EDDHA or $o, p$-EDDHA (and $\mathrm{EDDHA}_{m}$ in the biological experiment) were used for $\mathrm{Mn}$ and $\mathrm{Zn}$ in the formulations. The low $\mathrm{Zn}$ and specially $\mathrm{Mn}$ concentrations in soil measured in the batch experiment (Figure 1) when $o, p$-EDDHA was applied were a consequence of metals displacement by $\mathrm{Fe}$, as demonstrated by modeling (Figure 2). This displacement was higher in formulations containing $o, o-$ EDDHA, which chelated all micronutrients (Figure 2). The o,oEDDHA presents higher stability constants with $\mathrm{Fe}\left(\log \mathrm{K}_{\mathrm{ML}}^{0.1}\right.$ $o, o-\mathrm{EDDHA} / \mathrm{Fe}^{3+}=35.09$; Yunta et al., 2003) than with $\mathrm{Mn}$ or $\mathrm{Zn} \log \mathrm{K}_{\mathrm{MHL}}^{0.1} o, o$-EDDHA $/ \mathrm{Mn}^{2+}=19.89, \log \mathrm{K}_{\mathrm{ML}}^{0.1}$ o,oEDDHA $/ \mathrm{Zn}^{2+}=20.46$; López-Rayo et al., 2012) which explains these metal exchanges. These results agree with those of Gil-Ortiz and Bautista-Carrascosa (2004), who reported that chelation of Zn by $\mathrm{EDDHA}_{m}$ is negligible with Fe competition, preventing effective $\mathrm{Zn}$ chelation at soils $\mathrm{pH}$ close to 8.3. Furthermore, the competition with the $\mathrm{Cu}$ present in soil was high in formulations with $o, p$-EDDHA due to the high affinity of this ligand for $\mathrm{Cu}$ (Yunta et al., 2003; Schenkeveld et al., 2007). Byproducts contained in $\mathrm{EDDHA}_{m}$ may also contribute to this displacement since they contain the same functional groups. Also, the relatively low oxidizing conditions likely obtained in the batch experiments, because of the low soil/solution ratio $(5 \mathrm{~g} / 25 \mathrm{ml})$ may enhance the chelation of $\mathrm{EDDHA}_{m}$ with $\mathrm{Cu}$ (Hernández-Apaolaza et al., 2006). As a consequence of the above-mentioned effects, the combinations prepared with $\mathrm{EDDHA}_{m}$ were not efficient in providing $\mathrm{Mn}$ or $\mathrm{Zn}$ to soybean in the pot experiment. However, in hydroponics these ligands were efficient in providing $\mathrm{Mn}$ and $\mathrm{Zn}$ to plants (López-Rayo et al., 2012) indicating that a high proportion of these $\mathrm{Mn}$ and $\mathrm{Zn}$ chelates were the result of soil reactions. The input of metals in nutrient solution is controlled by the addition of equimolar amounts of ligand:metal with high affinity which limits the competition with metals. However, the contribution of sorbed metals and weakly-soluble forms in soils may increase with the presence of ligands, increasing competition for metals. Related to this, as well as $\mathrm{pH}$, redox conditions have been proven to be important factors affecting metal losses in all formulations. Manganese availability drastically decreased under relatively high-oxidizing conditions due to the formation of Mn oxides, similar to situations reported in hydroponics (López-Rayo et al., 

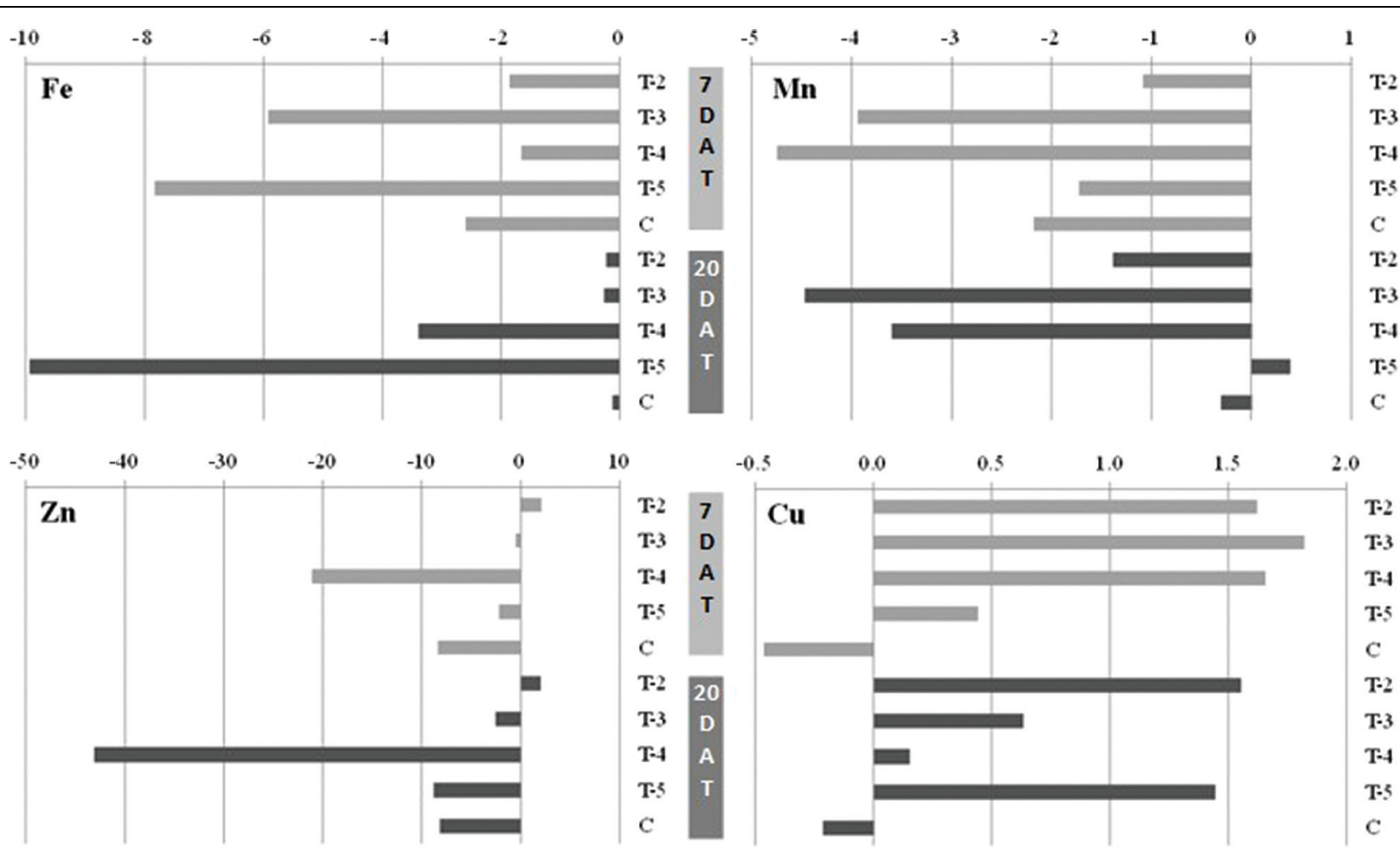

FIGURE 3 | CND indices for Fe, Mn, Zn, and Cu in the leaf of soybean plants $\mathbf{7}$ and 20 DAT. T-1 (o,o-EDDHA/Fe ${ }^{3+}$ MnZn-EDTA), was used as the norm so its value for all micronutrients is 0 .

2012), but $\mathrm{Zn}$ concentrations increased. This fact suggests that despite $\mathrm{Zn}$ concentrations being only slightly affected by redox conditions (López-Rayo et al., 2012), the amount of chelated $\mathrm{Zn}$ increased with the chelation of the free ligand resulting from $\mathrm{Mn}$ oxidation. Also, $\mathrm{Zn}$ solubilization from soil phases occurred (Figure 2). Our results present here and in other studies with multi-nutrient formulations (López-Rayo et al., 2012, 2015) demonstrate that, despite a preference for Fe binding by the $o, o$-EDDHA isomer, $\mathrm{Mn}$ and $\mathrm{Zn}$ competition with Fe occurs with the $o, p$-EDDHA isomer and the polycondensate products contained in the $\mathrm{EDDHA}_{m}$ formulations. This process plays an important role in the $\mathrm{Mn}$ and $\mathrm{Zn}$ availability to plants. These results disagree with those reported by Schenkeveld et al. (2007), which concluded that the Fe displacement by $\mathrm{Mn}$ and $\mathrm{Zn}$ in $\mathrm{EDDHA}_{m}-\mathrm{Fe}$ formulations is low.

S,S-EDDS was able to maintain $\mathrm{Zn}$ concentrations in soil solution and mobilize $\mathrm{Cu}$ into the soil solution (Figure 1). The relatively high stability constants of S,S-EDDS with $\mathrm{Cu}$ (II) $\left(\log \mathrm{K}^{0.1}=18.7\right)$ and $\mathrm{Zn}(\mathrm{II})\left(\log \mathrm{K}^{0.1}=13.6\right)$, and low with $\mathrm{Mn}(\mathrm{II})\left(\log \mathrm{K}^{0.1}=8.97\right.$; Orama et al., 2002$)$ supported these results. Tandy et al. (2006) reported that the exchange of S,SEDDS chelates with $\mathrm{Cu}$ occurred even in soils without elevated $\mathrm{Cu}$ contents, along with a high solubilization of $\mathrm{Zn}$ in soils, similar to the results observed in our experiments. Moreover, the results obtained in the soybean experiments indicated that the $\mathrm{Zn}$ can be efficiently provided by the S,S-EDDS formulations over a short time period (Table 3). However, over a longer period, its effectiveness is reduced, possibly due to competition with $\mathrm{Cu}$ and ligand degradation in soil. Repeated applications may increase its effectiveness and provide a solution with relatively low environmental impact.

The formulations containing IDHA resulted in low $\mathrm{Mn}$ and Zn stability in calcareous soil conditions as shown by the batch experiments (Figure 1) and therefore this combination was not selected for the plant experiment. IDHA metal chelates have lower stability constants $\left(\log \mathrm{K}_{\mathrm{Cu}(\mathrm{II}) \mathrm{L}}^{0.1}=12.9, \log \mathrm{K}_{\mathrm{Zn}(\mathrm{II}) \mathrm{L}}^{0.1}=\right.$ 10.2 , and $\log \mathrm{K}_{\mathrm{Mn}(\mathrm{II}) \mathrm{L}}^{0.1}=7.26$; Hyvönen et al., 2003) than S,S-EDDS, EDTA, HEEDTA, or DTPA chelates. However, an adequate supply of $\mathrm{Fe}, \mathrm{Mn}$ and $\mathrm{Zn}$ by IDHA chelates has been reported in field experiments in a soil-less culture similar or higher than EDTA (Lucena et al., 2008; López-Rayo et al., 2012) and by foliar application (Rodríguez-Lucena et al., 2010a,b). Thus, the metal losses from IDHA chelates are mainly associated with soil reactions that may also accelerate their biodegradation. A higher stability is expected at the lowest soil pHs (as predicted by the models), which may contribute to its effectiveness.

The ligands HEEDTA, EDTA, and DTPA maintained the highest $\mathrm{Mn}$ concentration in the soil solution (Figure 1). The formulation with DTPA maintained a high $\mathrm{Zn}$ stability to a similar extent as the formulation with S,S-EDDS (Figures 1 and 2). As a consequence, these two treatments also produced the highest $\mathrm{Zn}$ concentrations in soybean leaves. The EDTA formulation also reached similar $\mathrm{Zn}$ values. These ligands are known for their high capacity to extract metals in alkaline soils 
TABLE 4 | Soluble and available Fe, Mn, $\mathrm{Zn}$, and Cu extracted from soils 20 DAT.

\begin{tabular}{|c|c|c|c|c|c|c|c|c|c|}
\hline & & \multicolumn{4}{|c|}{ Soluble metal in soil $\left(\mathrm{mg} \mathrm{kg}^{-1}\right)$} & \multicolumn{4}{|c|}{ Available metal in soil $\left(\mathrm{mg} \mathrm{kg}^{-1}\right)$} \\
\hline $\mathrm{T}-1$ & o,o-EDDHA/Fe ${ }^{3+} \mathrm{MnZn-EDTA}$ & $0.298^{b c}$ & $0.0237^{a}$ & $0.0550^{\mathrm{b}}$ & $0.0398^{b}$ & $12.8 \mathrm{~ns}$ & $10.3 \mathrm{~ns}$ & $3.32 \mathrm{~ns}$ & $3.14 \mathrm{~ns}$ \\
\hline $\mathrm{T}-2$ & o,o-EDDHA $/ F e^{3+}$ MnZn-DTPA & $0.372^{\mathrm{a}}$ & $0.0142^{\mathrm{abc}}$ & $0.232^{\mathrm{a}}$ & $0.0981^{a}$ & 15.4 & 10.0 & 3.94 & 3.20 \\
\hline $\mathrm{T}-3$ & o,o-EDDHA $/ F^{3+} \mathrm{MnZn-EDDS}$ & $0.355^{\mathrm{ab}}$ & $0.0163^{\mathrm{ab}}$ & Bdl & $0.0365^{\mathrm{b}}$ & 15.3 & 13.1 & 4.48 & 4.25 \\
\hline $\mathrm{T}-4$ & FeMnZn-EDDHA $A_{m}$ & $0.261^{\mathrm{cd}}$ & $0.00227^{c}$ & Bdl & $0.0231^{b}$ & 16.4 & 12.0 & 4.07 & 4.25 \\
\hline
\end{tabular}

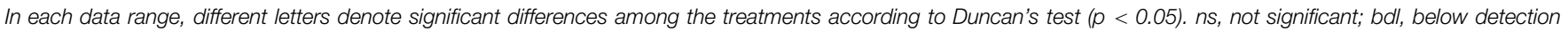
limit.

(Norvell, 1984), which contribute to the stabilization of metals in the assayed micronutrient formulations. However, neither of these, traditionally used in fertilization, provided sufficient leaf $\mathrm{Mn}$ levels in the soybean experiment (Table 3) suggesting that none of the assayed chelates led to recovery from the $\mathrm{Mn}$ deficiency induced in plants. The Mn concentrations after the experiments were in fact within the range of Mn deficiency in soybean as described by Malavolta et al. (2000), (10-20 mg kg-1). The low $\mathrm{Mn}$ concentrations distorted the $\mathrm{Fe} / \mathrm{Mn}$ ratios, and so high values were observed in all cases (Table 3). In any case, the evaluation of $\mathrm{Mn}$ nutrition using this ratio is not as clear as it is for Fe nutrition (Pestana et al., 2003) as was pointed out in hydroponics experiments using similar formulations (LópezRayo et al., 2015).

Although a high stability of $\mathrm{Zn}$ lignosulfonate and gluconate in alkaline solution has been reported (Lucena et al., 2010; Benedicto et al., 2011; López-Rayo et al., 2015), these materials showed lower stability in calcareous soil (Figure 1) compared to the chelates. Similarly, $\mathrm{Mn}$ lignosulfonate and gluconate have been shown to have low stability in calcareous and medium-pH soils
(López-Rayo et al., 2014). For this reason, their ability to provide $\mathrm{Mn}$ and $\mathrm{Zn}$ to soybean plants in calcareous soil was not assessed.

Regarding other nutritional aspects observed in the plant experiment, the formulations did not modify any of the analyzed growth parameters (Table 2). Although stem shortening is associated with Zn deficiency in plant (Marschner, 2012), a positive correlation of ID was found with leaf Mn concentration but not with $\mathrm{Zn}$, denoting that $\mathrm{Mn}$ deficiency may also negatively affect this growth parameter. Similar on effects observed in hydroponics (López-Rayo et al., 2015), a positive correlation was found between SPAD index and Fe concentration in leaves but not with the other micronutrients. The CND diagnostics (Figure 3) showed negative indices for $\mathrm{Fe}, \mathrm{Mn}$, and $\mathrm{Zn}$ in most of the formulations, indicating that they has a lower efficacy compared to EDTA-based formulation (T-1 used as the norm) in terms of overall plant nutrition.

According to the free ion activity model (FIAM) and the biotic ligand model (BLM), cells in general take up metals such as $\mathrm{Zn}$ and $\mathrm{Mn}$ from the soil solution only if they are present as free ions and not in the form of metal-organic complexes

Soil / solution
reactions 
(Hassler et al., 2004). The Fe uptake in all higher plants except for graminaceous (Strategy-I plants) is performed, in contrast, by the Fe chelate reductase enzyme (FCR); which activity requires the presence of $\mathrm{Fe}$ in soil solution as a Fe chelate for further reduction and uptake on the root surface (Römheld and Marschner, 1986). Thus, different biochemical processes are involved in the mechanisms for micronutrient uptake, which also differs when soil or hydroponic solutions are considered. In Figure 4, a schematic explanation of these processes is shown. When the chelate mixes are added to the system, chemical reactions limit their permanence in the nutrient/soil solution. In all cases, competition between the chelating agents and metals occurs. While metal substitution is slow in nutrient solution, the process is faster in soil (Figure 1). The addition of individual chelates with a high affinity ligand:metal can avoid competition between metals. In soil conditions, surface processes may decrease the presence of chelates in the soil solution, even if high affinity chelates are chosen. As mentioned above, Fe chelates are directly reduced by dicot plant roots due to the action of FCR, therefore, Fe uptake is in both cases (hydroponics and soil) favored by the more stable chelates in the corresponding conditions. It is also important to consider the reoxidation of $\mathrm{tFe}$, degradation of chelates and complexation of Fe(II) (Lucena, 2006). The use of chelating agents forming stable chelates with $\mathrm{Fe}$ (II) such as EDTA also reduce $\mathrm{Fe}$ uptake due to ligand-root competition for the metal. The ligand-root competition for the metal is the key factor in understanding the different behaviors between hydroponics and soil systems for $\mathrm{Zn}$ and $\mathrm{Mn}$. The uptake of the $\mathrm{Zn}^{2+}$ and $\mathrm{Mn}^{2+}$ mentioned in the FIAM and BLM models requires the dissociation of the metal chelates at the root surface (Degryse et al., 2006; Wang et al., 2009) which increase the concentration of free ligand and then decrease the free ion activity:

$$
\mathrm{ZnY} \rightleftarrows \mathrm{Zn}^{2+}+\mathrm{Y} ; \quad \log \left(\mathrm{Zn}^{2+}\right)=-\log \mathrm{K}^{0}+\log \frac{\mathrm{ZnY}}{\mathrm{Y}}
$$

The binding strength of the respective metal-ligand chelates is a crucial factor in this process (Degryse et al., 2006; Wang et al., 2009). In hydroponics, very stable chelates (large $\log \mathrm{K}^{0}$ ) led to a dramatic decrease in the metal ion activity, preventing plant uptake. However, in soil conditions the free ligand easily chelates the metal (or other metal competitors) so the $\frac{(\mathrm{ZnY})}{(\mathrm{Y})}$ ratio hardly decreases at all. In other words, the ligand is a competitor for metal uptake in the plant and a carrier in soil conditions. Besides these mechanisms affecting the individual metal chelate uptake, the metals competition plays a very important role, as shown by our early-mentioned results.

\section{References}

Akay, A., and Kaya, M. H. (2007). Effect of zinc-containing fertilizers in organic and inorganic forms on the yield of barley crop and uptake of nutrients. Asian J. Chem. 19, 627-635.

Álvarez, J. M., and Rico, M. I. (2003). Effects of zinc complexes on the distribution of zinc in calcareous soil and zinc uptake by maize. J. Agric. Food Chem. 51, 5760-5767. doi: 10.1021/jf0 $30092 \mathrm{~m}$

\section{Conclusion}

Chelates of low stability were more reactive under calcareous soil conditions, and were consequently less effective at providing micronutrients to soybean. Therefore, the most stable chelates are preferred, in contrast to those required for hydroponics. Formulations containing $\mathrm{EDDHA}_{m}$ did not supply sufficient amounts of $\mathrm{Zn}$ to plants since low concentrations of chelates were present in the soil solution due to their interaction with Fe and soil constituents. A similar tendency is expected for IDHA, lignosulfonate and gluconate formulations based on the low stability observed in the batch and modeling experiments. A multi-nutrient formulation containing S,S-EDDS may adequately provide $\mathrm{Zn}$ at a similar rate to EDTA but a more frequent application must be considered for long experiments. Any of the ligands studied, novel or traditional, when included in one of the formulations, resulted in a sufficient leaf $\mathrm{Mn}$ concentration. These results highlight the need to explore other sources to include $\mathrm{Mn}$ in multi-nutrient formulations (but also in simple additions) in soil applications to provide sufficient amounts of $\mathrm{Mn}$ to plants growing in calcareous soils.

\section{Author Contributions}

SL did the batch and plant experiments and the subsequent analysis, and statistical analysis with the help of PN. Modeling was performed by SL and JJL. SL wrote the manuscript together with the revision of JJL. JJL designed the manuscript and supervised all the experimental work presented.

\section{Acknowledgments}

This work was supported by the Spanish MINECO Project AGL2013-44474-R from Ministerio de Economía y Competitividad. Also, Syngenta Agro S.L support is appreciated. The authors wish to thank Mr. Sean Case and Prof. Kristian Holst Lauren for the proof-reading of the manuscript.

\section{Supplementary Material}

The Supplementary Material for this article can be found online at: http://journal.frontiersin.org/article/10.3389/fpls.2015.00752

Álvarez-Fernández, A., Pérez-Sanz, A., and Lucena, J. J. (2001). Evaluation of effect of washing procedures on minerals analysis of orange and peach leaves sprayed with seaweed extracts enriched with iron. Commun. Soil Sci. Plant Anal. 32, 157-170. doi: 10.1081/CSS-100103000

Álvarez-Fernández, A., Sierra, M. A., and Lucena, J. J. (2002). Reactivity of synthetic Fe chelates with soils and soil components. Plant Soil 241, 129-137. doi: 10.1023/A:1016012513044

Aye, K. S. (2011). Investigation on the effectiveness of zinc sulphate and biofertilizer on mustard plant. World Acad. Sci. Eng. Technol. 75, 335-337. 
Benedicto, A., Hernández-Apaolaza, L., Rivas, I., and Lucena, J. J. (2011). Determination of $67 \mathrm{Zn}$ distribution in navy bean (Phaseolus vulgaris L.) after foliar application of $67 \mathrm{Zn}$ lignosulfonates using isotope pattern deconvolution. J. Agric. Food Chem. 59, 8829-8838. doi: 10.1021/jf2002574

Comité Européen de Normalisation [CEN]. (2008). EN 15452:2008. Fertilizers Determination of Chelating Agents - Determination of Iron Chelated by o,pEDDHA by Reversed Phase HPLC. London: BSI.

Degryse, F., Smolders, E., and Parker, D. R. (2006). Metal complexes increase uptake of $\mathrm{Zn}$ and $\mathrm{Cu}$ by plants: implications for uptake and deficiency studies in chelator-buffered solutions. Plant Soil 289, 171-185. doi: 10.1007/s11104-0069121-4

Gangloff, W., Westfall, D., Peterson, G., and Mortvedt, J. J. (2006). Mobility of organic and inorganic zinc fertilizers in soils. Soil Sci. Plant Anal. 37, 199-209. doi: 10.1080/00103620500403200

García-Marco, S., Martínez, N., Yunta, F., Hernández-Apaolaza, L., and Lucena, J. J. (2006). Effectiveness of ethylenediamine- $N$-(o-hydroxyphenylacetic)- $N^{\prime}-$ ( $p$-hydroxyphenylacetic) acid (o,p-EDDHA) to supply iron to plants. Plant Soil 279, 31-40. doi: 10.1007/s11104-005-8218-5

Gil-Ortiz, R., and Bautista-Carrascosa, I. (2004). Effects of Fe-EDDHA chelate application on evolution of soil extractable iron, copper, manganese and zinc. Commum. Soil Sci. Plant Anal. 25, 559-570. doi: 10.1081/CSS-120029732

Gómez-Gallego, M., Sierra, M. A., Alcázar, R., Ramírez, P., Piñar, C., Mancheño, M. J., et al. (2002). Synthesis of o,p-EDDHA and its detection as the main impurity in o,o-EDDHA iron chelates. J. Agric. Food Chem. 50, 6395-6399. doi: $10.1021 / \mathrm{jf} 025727 \mathrm{~g}$

González, D., Obrador, A., and Álvarez, J. M. (2007). Behavior of zinc from six organic fertilizers applied to a navy bean crop grown in a calcareous soil. J. Agric. Food Chem. 55, 7084-7092. doi: 10.1021/jf071090v

Hassler, C. S., Slaveykova, V. I., and Wilkinson, K. J. (2004). Some fundamental (and often overlooked) considerations underlying the free ion activity and biotic ligand models. Environ. Toxicol. Chem. 23, 283-291. doi: 10.1897/03-149

Hernández-Apaolaza, L., García-Marco, S., Nadal, P., Lucena, J. J., Sierra, M. A., Gómez-Gallego, M., et al. (2006). Structure and fertilizer properties of byproducts formed in the synthesis of EDDHA. J. Agric. Food Chem. 54, 4355-4363. doi: 10.1021/jf0605749

Hyvönen, H., Orama, M., Saarinen, H., and Aksela, R. (2003). Studies on biodegradable chelating ligands: complexation of iminodisuccinic acid (ISA) with $\mathrm{Cu}(\mathrm{II}), \mathrm{Zn}(\mathrm{II}), \mathrm{Mn}(\mathrm{II})$ and $\mathrm{Fe}(\mathrm{III})$ ions in aqueous solution. Green Chem. $5,410-414$.

Laurie, S. H., Tancock, N. P., Mcgrath, S. P., and Sanders, R. (1991). Influence of complexation on the uptake by plants of iron, manganese, copper and zinc. J. Exp. Bot. 42, 509-513. doi: 10.1093/jxb/42. 4.515

Liñán, C. (2014). "Correctores de carencias de manganeso," in Vademecum de Productos Fitosanitarios y Nutricionales, eds C. de Liñán Carral and C. de Liñán Vicente (Madrid: Agrotécnicas, S.L).

Lindenmayer, R. (2007). Zinc Fertilization: A Review of Scientific Literature. Fort Collins, CO: Colorado State University.

Lindsay, W. L., and Schwab, A. P. (1982). The chem-istry of iron in soils and its availability to plants. J. Plant Nutr. 5, 821-840. doi: $10.1080 / 01904168209363012$

López-Rayo, S., Correas, C., and Lucena, J. J. (2012). Novel chelating agents for its use as manganese and zinc fertilizers: characterization, theoretical speciation and stability in solution. Chem. Spec. Bioavailab. 24, 147-158. doi: 10.3184/095422912X13409631969915

López-Rayo, S., Lucena, S., and Lucena, J. J. (2014). Chemical properties and reactivity of manganese chelates and complexes in solution and soils. J. Plant Nutr. Soil Sci. 177, 189-198. doi: 10.1002/jpln.2013 00091

López-Rayo, S., Nadal, P., and Lucena, J. J. (2015). Novel chelating agents for iron, manganese, zinc, and copper mixed fertilisation in high $\mathrm{pH}$ soil-less cultures Iron, manganese, zinc and copper chelate formulations for hydroponics at high pH. J. Sci. Food Agric. doi: 10.1002/jsfa.7183 [Epub ahead of print].

López-Rayo, S., Nadal, P., Pozo, M. A., Domínguez, A., and Lucena, J. J. (2013). Efficacy of micronutrient chelate treatments in commercial crop of strawberry on sand culture. Commun. Soil Sci. Plant Anal. 44, 826-836. doi: 10.1080/00103624.2013. 749440
Lucena, J. J. (2006). "Synthetic iron chelates to correct iron deficiency in plants," in Iron Nutrition in Plants and Rhizospheric Microorganism, eds L. L. Barton and J. Abadía (New York, NY: Kluwer Academic Publishers), 103-128.

Lucena, J. J., Gárate, A., and Villén, M. (2010). Stability in solution and reactivity with soils and soil components of iron and zinc complexes. J. Plant Nutr. Soil Sci. 173, 900-906. doi: 10.1002/jpln.200900154

Lucena, J. J., Sentís, J. A., Villén, M., Lao, T., and Pérez-Sáez, M. (2008). IDHA chelates as a micronutrient source for green bean and tomato in fertigation and hydroponics. Agron. J. 100, 813-818. doi: 10.2134/agronj2007.0257

Malavolta, E., Cabral, C. P., and Lavres, O. A. J. Jr. (2000). Efeitos do manganês sobre a soja cultivada em solo de cerrado do triângulo mineiro. Pesq. Agropec. Bras. 35, 1629-1636. doi: 10.1590/S0100-204X200000 0800016

Marschner, H. (2012). Mineral Nutrition of Higher Plants. London: Academic Press. Martín-Ortiz, D., Hernández-Apaolaza, L., and Gárate, A. (2009). Efficiency of a zinc lignosulfonate as $\mathrm{Zn}$ source for wheat (Triticum aestivum L.) and corn (Zea mays L.) under hydroponic culture conditions. J. Agric. Food Chem. 57, 226-231. doi: $10.1021 / \mathrm{jf} 8030869$

Nadal, P., García-Delgado, C., Hernández, D., López-Rayo, S., and Lucena, J. J. (2012). Evaluation of Fe-N,N'-Bis(2-hydroxybenzyl)ethylenediamine-N,N'diacetate (HBED/Fe3+) as Fe carrier for soybean (Glycine max) plants grown in calcareous soil. Plant Soil 360, 349-362. doi: 10.1007/s11104-012-1246-Z

Nawrocki, A., Stefaniak, F., Mrozek-Niecko, A., and Olszewski, R. (Przedsiebiorstwo Produkcyjno-Consultingowe Adob) (2009). Preparation of $\mathrm{N}, \mathrm{N}^{\prime}$-bis(2-hydroxybenzyl)ethylenediamine-N,N'-diacetic acid and its derivatives. PCT Int. Appl. 30, WO 2009/037235 A1 20090326.

Norvell, W. A. (1984). Comparison of chelating agents as extractants for metals in diverse soil materials. Soil Sci. Soc. Am. J. 48, 1285-1292. doi: 10.2136/sssaj1984.03615995004800060017x

Norvell, W. A. (1991). "Reactions of metal chelates in soils and nutrient solutions," in Micronutrients in Agriculture, ed. J. J. Mortvedt (Madison, WI: Soil Science Society of America), 187-227.

Orama, M., Hyvönen, H., Saarinen, H., and Aksela, R. (2002). Complexation of $[\mathrm{S}, \mathrm{S}]$ and mixed stereoisomers of $\mathrm{N}, \mathrm{N}^{\prime}$-ethylenediaminedisuccinic acid (EDDS) with $\mathrm{Fe}(\mathrm{III}), \mathrm{Cu}(\mathrm{II}), \mathrm{Zn}(\mathrm{II})$ and $\mathrm{Mn}(\mathrm{II})$ ions in aqueous solution. J. Chem. Soc. Dalton Trans. 24, 4644-4648. doi: 10.1039/b207777a

Pestana, M., de Varennes, A., and Araujo Faria, E. (2003). Diagnosis and correction of iron chlorosis in fruit tres. A review. J. Food Agric. Environ. 1, 46-51.

Rodríguez-Lucena, P., Hernández-Apaolaza, L., and Lucena, J. J. (2010a). Comparison of iron chelates and complexes supplied as foliar sprays and in nutrient solution to correct iron chlorosis of soybean. J. Plant Nutr. Soil Sci. 173, 120-126. doi: 10.1002/jpln.200800256

Rodríguez-Lucena, P., Ropero, E., Hernández-Apaolaza, L., and Lucena, J. J. (2010b). Iron supply to soybean plants through the foliar application of IDHA/Fe3+: effect of plant nutrition status and adjuvants. J. Sci. Food Agric. 90, 2633-2640. doi: 10.1002/jsfa.4132

Rojas, C. L., Romera, F. J., Alcántara, E., Pérez-Vicente, R., Sariego, C., GarcíaAlonso, I., et al. (2008). Efficacy of Fe(o,o-EDDHA) and Fe(o,p-EDDHA) isomers in supplying Fe to strategy I plants differs in nutrient solution and calcareous soil. J. Agric. Food Chem. 56, 10774-10778. doi: 10.1021/jf80 22589

Römheld, V., and Marschner, H. (1986). Evidence for a specific uptake system for iron phytosiderophores in roots of grasses. Plant Physiol. 80, 175-180. doi: 10.1104/pp.80.1.175

Schenkeveld, W. D. C., Reichwein, A. M., Bugter, M. H. J., Temminghoff, E. J. M., and van Riemsdijk, W. H. (2010). Performance of soil-applied FeEDDHA isomers in delivering $\mathrm{Fe}$ to soybean plants in relation to the moment of application. J. Agric. Food Chem. 58, 12833-12839. doi: 10.1021/jf102011w

Schenkeveld, W. D. C., Reichwein, A. M., Temminghoff, E. J. M., and Riemsdijk, W. H. (2007). The behaviour of EDDHA isomers in soils as influenced by soil properties. Plant Soil 290, 85-102. doi: 10.1007/s11104-006-9135-y

Soltanpour, P. N., and Schwab, A. P. (1977). A new soil test for simultaneous extraction of macro- and micronutrients in alkaline soils. Commum. Soil Sci. Plant Anal. 8, 195-207. doi: 10.1080/00103627709366714

Tandy, S., Ammann, A., Schulin, R., and Nowack, B. (2006). Biodegradation and speciation of residual SS-ethylenediaminedisuccinic acid (EDDS) in soil solution left after soil washing. Environ. Pollut. 142, 191-199. doi: 10.1016/j.envpol.2005.10.013 
Vandevivere, P. C., Saveyn, H., Verstraete, W., Feijtel, T., and Schowanek, T. (2001). Biodegradation of Metal-[S,S]-EDDS complexes. Environ. Sci. Technol. 35, 1765-1770. doi: 10.1021/es0001153

Villén, M., García-Arsuaga, A., and Lucena, J. J. (2007a). Potential use of biodegradable chelate $\mathrm{N}$-(1,2-dicarboxyethyl)-D,L-aspartic acid/Fe3+ as an Fe fertilizer. J. Agric. Food Chem. 55, 402-407. doi: 10.1021/jf062471w

Villén, M., Lucena, J. J., Cartagena, M. C., Bravo, R., García-Mina, J. M., and Hinojosa, I. M. (2007b). Comparison of two analytical methods for the evaluation of the complexed metal in fertilizers and the complexing capacity of complexing agents. J. Agric. Food Chem. 55, 5746-5753. doi: 10.1021/jf0 $70422 \mathrm{t}$

Wang, P., Zhou, D. M., Luo, X. S., and Li, L. Z. (2009). Effects of Zn-complexes on zinc uptake by wheat (Triticum aestivum) roots: a comprehensive consideration of physical, chemical and biological processes on biouptake. Plant Soil 316, 177-192. doi: 10.1007/s11104-008-9769-z

Yunta, F., García-Marco, S., and Lucena, J. J. (2003). Theoretical speciation of ethylenediamine- $\mathrm{N}$-(o-hydroxyphenylacetic)- $\mathrm{N}$-(p-hydroxyphenylacetic) acid
(o,p-EDDHA) in agronomic conditions. J. Agric. Food Chem. 51, 5391-5399. doi: $10.1021 / \mathrm{jf} 034304 \mathrm{r}$

Yunta, F., López-Rayo, S., and Lucena, J. J. (2012). Thermodynamic database update to model synthetic chelating agents in soil systems. J. Appl. Sol. Chem. Model. 1, 46-64.

Conflict of Interest Statement: The authors declare that the research was conducted in the absence of any commercial or financial relationships that could be construed as a potential conflict of interest.

Copyright (c) 2015 López-Rayo, Nadal and Lucena. This is an open-access article distributed under the terms of the Creative Commons Attribution License (CC BY). The use, distribution or reproduction in other forums is permitted, provided the original author $(s)$ or licensor are credited and that the original publication in this journal is cited, in accordance with accepted academic practice. No use, distribution or reproduction is permitted which does not comply with these terms. 